\title{
Diagnostic performance of the Minimal Eating Observation and Nutrition Form - Version II (MEONF-II) and Nutritional Risk Screening 2002 (NRS 2002) among hospital inpatients - a cross- sectional study
}

\author{
Albert Westergren $^{1 *}$, Erika Norberg ${ }^{2}$ and Peter Hagell ${ }^{1}$
}

\begin{abstract}
Background: The usefulness of the nutritional screening tool Minimal Eating Observation and Nutrition Form Version II (MEONF-II) relative to Nutritional Risk Screening 2002 (NRS 2002) remains untested. Here we attempted to fill this gap by testing the diagnostic performance and user-friendliness of the MEONF-II and the NRS 2002 in relation to the Mini Nutritional Assessment (MNA) among hospital inpatients.

Methods: Eighty seven hospital inpatients were assessed for nutritional status with the 18-item MNA (considered as the gold standard), and screened with the NRS 2002 and the MEONF-II.

Results: The MEONF-II sensitivity (0.61), specificity (0.79), and accuracy (0.68) were acceptable. The corresponding figures for NRS 2002 were 0.37, 0.82 and 0.55, respectively. MEONF-II and NRS 2002 took five minutes each to complete. Assessors considered MEONF-II instructions and items to be easy to understand and complete (96-99\%), and the items to be relevant (87\%). For NRS 2002, the corresponding figures were $75-93 \%$ and $79 \%$, respectively.

Conclusions: The MEONF-II is an easy to use, relatively quick and sensitive screening tool to assess risk of undernutrition among hospital inpatients. With respect to user-friendliness and sensitivity the MEONF-II seems to perform better than the NRS 2002, although larger studies are needed for firm conclusions. The different scoring systems for undernutrition appear to identify overlapping but not identical patient groups. A potential limitation with the study is that the MNA was used as gold standard among patients younger than 65 years.
\end{abstract}

\section{Background}

Undernutrition is associated with poorer health, compromised ability to recover from medical conditions and increased mortality [1]. People at risk for or with manifest undernutrition therefore need to be identified in order to initiate prevention or interventions. Low Body Mass Index (BMI) and unintentional weight loss are considered key indicators of undernutrition [2], and together with change in food intake these indicators are associated with changes in function and clinical

\footnotetext{
* Correspondence: Albert.Westergren@hkr.se

'The PRO-CARE group, School of Health and Society, Kristianstad University, Kristianstad, Sweden

Full list of author information is available at the end of the article
}

outcome [3]. This is reflected in commonly used nutritional screening tools such as the Nutritional Risk Screening 2002 (NRS 2002; [4]), the Mini Nutritional Assessment (MNA; [5,6] ), Malnutrition Universal Screening Tool (MUST; [7]) and the recently developed Minimal Eating Observation and Nutrition Form - Version II (MEONF-II; $[8,9]$ ).

In Sweden, it is recommended that undernutrition risk screening should include at least the following three criteria: unintentional weight loss, eating difficulties, and low BMI [10]. These criteria were recently operationalized in the MEONF-I [11] and its subsequent modification MEONF-II [8,9]. While the NRS 2002 and MNA

\section{() Biomed Central}


have been widely used for years, the MEONF-II was only recently introduced $[8,9]$.

MEONF-II is based within an interdisciplinary nursing framework, combining descriptions of mealtime problems with classical signs of undernutrition in order to facilitate detection of problems in need of interventions $[8,9]$. In a previous study, the sensitivity, specificity and user-friendliness of the MEONF-II and MUST in relation to the MNA was analyzed among elderly ( $>65$ years) orthopaedic, cardiology and stroke inpatients. The MEONF-II was found to be easy and relatively quick to use with a sensitivity of 0.68 , which was favourable to that of the MUST (0.57) [8]. However, its usefulness relative to the NRS 2002 remains untested. Here we attempted to fill this gap by testing the MEONF-II and NRS 2002 in relation to the MNA among hospital inpatients.

\section{Methods \\ Sample}

Ninety six persons (18+ years old) receiving inpatient care at four wards (stroke, surgery, orthopaedic, internal medicine) at a hospital in southern Sweden were approached. Fifteen of the patients were younger than 65 years. There were no predefined inclusion or exclusion criteria used. Data from 87 patients were analyzed. Reasons for not participating $(\mathrm{n}=7)$ were aphasia $(\mathrm{n}=$ $1)$, language difficulties $(n=1)$, dementia $(n=1)$, mental illness $(n=1)$, and not wanting to participate $(n=3)$. In another two cases the forms were incomplete and had to be excluded. Informed consent was obtained. The sample has previously been used as part of a larger study regarding MEONF-II cut-off scores [9]. The study was approved by the local ethics council at Kristianstad University.

\section{Assessments}

Background data (i.e. age, sex, admitted to hospital from own home/special accommodation, and cohabitation) were recorded and assessments were conducted according to the MNA, MEONF-II and NRS 2002.

\section{Mini Nutritional Assessment (MNA)}

The MNA was developed for use among elderly patients ( $\geq 65$ years) $[12,13]$. The full MNA consists of 18 items with a maximum possible total score of 30 . The cut-off values for MNA have been defined based on serum albumin levels $[13,14]$. A score below 17 is indicative of undernutrition, patients scoring 17 to 23.5 are at risk for undernutrition, and patients with a score of 24 or more are considered well-nourished [13,14]. The tool has been shown to have high sensitivity (96\%), specificity (98\%), and positive predictive value (97\%) when compared with extensive assessments of patients' nutritional status [6]. Here we used the 18-item MNA as the gold standard for determination of nutritional status.

\section{Nutritional Risk Screening 2002 (NRS 2002)}

The main purpose of the NRS 2002 is to identify patients who may benefit from nutritional interventions [4]. It consists of four initial screening questions: 1 ) is BMI < 20.5?; 2) has intake been reduced during the last week?; 3) has there been a recent weight loss?; 4) is the patient severely ill? Patients without any affirmative responses to the four initial screening questions were classified as "not at nutritional risk". A positive response to $\geq 1$ of these four questions prompts a formal screening that is characterized by scoring two components, undernutrition and severity of disease. The undernutrition component comprises BMI, percent recent weight loss and recent change in food intake; the disease severity component considers increase in nutritional requirements resulting from disease, i.e. stress-metabolism. A score of 0-3 (representing absent, mild, moderate and severe) is assigned to each of the two components. In addition, a score of one is added for people $\geq 70$ years old. Thus, the final score can range from 0-7. A score of 3 or above is considered signalling nutritional risk. The cut-off value for NRS 2002 has been identified by a retrospective classification, and application of cut-off scores in randomized controlled trials identifying the effect of nutritional intervention (typically artificial nutrition) on clinical outcome as positive or absent, and by using receiver operating characteristic curve (ROC analysis) [4]. In a previous study among geriatric ( $>65$ years) hospital patients, the NRS 2002 had a sensitivity of 0.39 , specificity of 0.83 , positive and negative predictive values of 0.84 and 0.37 , respectively, and an accuracy of 0.52 when compared with the MNA [15].

\section{Minimal Eating Observation and Nutrition Form - Version II (MEONF-II)}

MEONF (additional file 1) was developed from the Minimal Eating Observation Form - Version II (MEOFII) $[16,17]$ and the criteria unintentional weight loss, either low BMI (<20 for 69 years or younger, or $<22$ for 70 years or older) [10] or calf circumference $<31$ centimeters, and an additional assessment of the presence or absence of clinical signs of undernutrition [8]. MEOF-II includes three components of eating. Food intake includes "difficulty manipulating food on plate", "difficulty conveying food to the mouth" and "difficulty to maintain good sitting position during meals". Swallowing/mouth includes "difficulty chewing", "difficulty coping with food in mouth" and "difficulty swallowing". Energy/appetite includes "lacks energy to complete an entire meal", "poor appetite" and "eats less than 3/4 of food served" [16]. In MEONF-II all items are scored 1 
except for unintentional weight loss and energy/appetite, which are scored 2 since such problems are significant indicators or predictors of undernutrition $[2,16,17]$. MEONF-II yields a total score ranging from 0-8. A score of 0-2 is interpreted as low risk for undernutrition, a score of 3-4 is considered a moderate risk, and a score $\geq 5$ as high risk for undernutrition [8]. These cut-off scores were initially based on clinical reasoning [8], and later confirmed by using ROC analysis comparing MEONF-II scores against the MNA classification [9]. Among patients older than 65 years, MEONF-II has shown a sensitivity of 0.73 , specificity 0.88 , positive predictive value 0.81 , negative predictive value 0.82 , and accuracy of 0.82 when compared with the MNA [8].

\section{Procedure}

Patients were assessed during the first four days after admission. Data were collected by one nurse on each ward (each having special responsibility for nutrition at their respective wards) during one set day in November 2010.

The order of the nutritional assessments in the protocol was, first MEONF-II, thereafter NRS 2002, and finally MNA. Meal-time observations (MEONF-II) were conducted during lunch or dinner. Height and weight were recorded in the morning and other observations at convenient time points during the day. The four nurses received written and oral information about the study and the included assessment methods. The information was provided to the four nurses in a single group session lasting for about one hour the day before data collection. The researchers were available to answer questions during the data collection day.

User-friendliness of the three tools was evaluated by recording the time required to complete each tool and by inquiring the assessors of their perceived ease of understanding and following instructions, ease of understanding and completing items, and whether items were perceived as relevant. This was done following each patient assessment $(\mathrm{n}=87)$.

\section{Analyses}

The diagnostic performance of the MEONF-II and NRS 2002 was assessed by calculating the sensitivity, specificity, positive and negative predictive values (PPV and NPV, respectively) and accuracy $[18,19]$, using results from the 18-item MNA as the comparator gold standard. These indices provide values ranging from zero to one (or, equivalently expressed as a percentage), where higher values are preferred [18,19]. For these analyses, patients with undernutrition and those at risk for undernutrition according to the MNA were collapsed into one group. Similarly, patients with moderate and high risk for undernutrition according to the MEONF-II were collapsed into one group. 95\% confidence intervals (CIs) were constructed for sensitivity, specificity, PPV and NPV; non-overlapping 95\% CIs between NRS 2002 and MEONF-II was regarded statistically significant. Since the MNA was developed for people >65 years of age, data were also analyzed with people younger than 65 years excluded $(n=15)$.

Time to complete the three screening tools was analyzed by Friedman's two-way analysis of variance by ranks followed by post-hoc Wilcoxon signed ranks tests. Other user-friendliness data, and undernutrition risk according to the three tools were analyzed using Cochran's $\mathrm{Q}$ test followed by post-hoc analyses (McNemar). P-values were considered significant if $<0.05$ (following Bonferroni corrections in post-hoc analyses)[18]. Analyses were conducted using PASW Statistics 18.0.

\section{Results}

Demographical data are presented in Table 1.

The proportion of people classified as at risk for undernutrition according to NRS 2002 (29\%) was significantly lower than found using MEONF-II (45\% at moderate/high risk, $\mathrm{p}=0.007)$ and MNA $(60 \%$ at risk for undernutrition/undernourished, $\mathrm{p}<0.0005)$. There was no significant difference $(\mathrm{p}=0.021)$ in proportions found using the MEONF-II and MNA following Bonferroni correction $(\mathrm{p}=0.063)$ (Table 2$)$. Out of 18 undernourished patients according to MNA 13 were considered being at high risk according to MEONF-II, and 12 as at risk for undernutrition according to NRS 2002. Out of 22 patients at high risk according to MEONF-II, 13 were considered undernourished according to MNA, and 12 as at risk according to NRS 2002.

The sensitivity (i.e., proportion of people correctly identified as at risk for undernutrition according to the 18-item MNA) of the MEONF-II was 61\% (Table 3). For the NRS 2002, sensitivity was $37 \%$. That is, the two methods missed $39 \%$ and $63 \%$, respectively, of cases identified as at risk for or being undernourished according to the MNA. The specificity (i.e., proportion of people correctly identified as not at risk for undernutrition according to the 18-item MNA) for the MEONF-II was $79 \%$, and for the NRS 2002 it was $82 \%$ (Table 3).

A positive MEONF-II result, indicating risk for undernutrition, was associated with a PPV of $82 \%$; that is, a $82 \%$ probability that the individual really was undernourished (according to the 18-item MNA). A negative MEONF-II result was associated with a NPV of $57 \%$; that is, a $57 \%$ probability that the individual really was not undernourished. For the NRS 2002, PPV and NPV were $76 \%$ and $47 \%$, respectively. The exact proportions of agreement (accuracies) according to the various methods were $68 \%$ for MEONF-II and $55 \%$ for NRS 2002 in relation to the 18-item MNA (Table 3). 


\begin{tabular}{|c|c|c|c|c|c|}
\hline & \multicolumn{4}{|c|}{ Ward } & \multirow[b]{2}{*}{$\begin{array}{c}\text { Total } \\
\mathrm{n}=87\end{array}$} \\
\hline & $\begin{array}{l}\text { Stroke } \\
n=21\end{array}$ & $\begin{array}{c}\text { Surgery } \\
n=19\end{array}$ & $\begin{array}{c}\text { Orthopaedic } \\
n=23\end{array}$ & $\begin{array}{l}\text { Geriatric Medicine } \\
n=24\end{array}$ & \\
\hline \multicolumn{6}{|l|}{ Age } \\
\hline mean $(\mathrm{SD})$ & $72.1(18.1)$ & $69.6(13.7)$ & $75.0(15.8)$ & $82.6(8.6)$ & $74.8(15.1)$ \\
\hline $\min -\max$ & 23-91 & 41-88 & $37-92$ & 58-98 & 23-98 \\
\hline \multicolumn{6}{|l|}{ Sex } \\
\hline Women, n (\%) & $11(52)$ & $8(42)$ & $12(52)$ & $17(71)$ & $48(55)$ \\
\hline Men, n (\%) & $10(48)$ & $11(58)$ & $11(48)$ & $7(29)$ & $39(45)$ \\
\hline \multicolumn{6}{|l|}{ Admitted to hospital from ${ }^{1}$} \\
\hline Ordinary/own home, n (\%) & $20(95)$ & $19(100)$ & $20(87)$ & $22(96)$ & $81(94)$ \\
\hline Special accomodation, n (\%) & $1(5)$ & 0 & $3(13)$ & $1(4)$ & $5(6)$ \\
\hline \multicolumn{6}{|l|}{ Cohabitation $^{2}$} \\
\hline Married/living with someone, n (\%) & $10(48)$ & $10(56)$ & $9(45)$ & $8(35)$ & $37(45)$ \\
\hline Alone, n (\%) & $11(52)$ & $8(44)$ & $11(55)$ & $15(65)$ & $45(55)$ \\
\hline
\end{tabular}

1) Internal attrition/drop-out $n=2$

2) Internal attrition/drop-out $n=5$

Overlapping 95\% CIs between the NRS 2002 and MEONF-II suggested no statistically significant differences in sensitivity, specificity, PPV and NPV between these tools.

Analyses of data only from those $\geq 65$ years old ( $\mathrm{n}=$ 72) yielded similar results for both the MEONF-II (sensitivity, 57\%; specificity, 79\%; PPV, 80\%; NPV, 56\%; accuracy, 66\%) and NRS 2002 (sensitivity, 36\%; specificity, 79\%; PPV, 71\%; NPV, 46\%; accuracy, 53\%).

The median time required to conduct assessments according to the NRS 2002 and MEONF-II was 5 minutes each; in contrast, the 18-item MNA took twice as long to complete (Table 4). Assessors considered the MEONF-II instructions and items easy to understand and complete (96-99\%), and its items to be relevant (87\%). For the NRS 2002, the corresponding figures were $75-93 \%$ and 79\%, respectively. Both the NRS 2002 and MEONF-II were significantly quicker to complete than the MNA (Table 4). Items of the MNA and MEONF-II were considered easier to understand compared to NRS 2002 items, and MEONF-II items were considered easier to answer than NRS 2002 items (Table 4).

\section{Discussion}

This study provides support for the validity and userfriendliness of the MEONF-II and the NRS 2002. Perceived user-friendliness of the MEONF-II was somewhat better than that of the NRS 2002. It was indicated, although not significantly, that the MEONF-II had better sensitivity than the NRS 2002 in comparison to the MNA.

Table 2 Percentage of individuals classified as at risk of undernutrition (UN)

\begin{tabular}{|c|c|c|c|c|c|}
\hline & & & Ward & & \\
\hline & Stroke & Surgery & Orthopaedic & Geriatric Medicine & Total \\
\hline & $\mathrm{n}=21$ & $n=19$ & $n=23$ & $n=24$ & $\mathrm{n}=87$ \\
\hline MEONF-II, n (\%) & & & & & \\
\hline Low risk for UN (0-2 points) & $11(52)$ & $11(58)$ & $12(52)$ & $14(58)$ & $48(55)$ \\
\hline Moderate risk for UN (3-4 points) & $5(24)$ & $3(16)$ & $3(13)$ & $6(25)$ & $17(20)$ \\
\hline High risk for UN ( $\geq 5$ points) & $5(24)$ & $5(26)$ & $8(35)$ & $4(17)$ & $22(25)$ \\
\hline NRS 2002, n (\%) ${ }^{1}$ & & & & & \\
\hline No risk for UN ( $\leq 3$ points) & $15(71)$ & $16(84)$ & $16(73)$ & $14(58)$ & $61(71)$ \\
\hline Risk for UN ( $\geq 3$ points) & $6(29)$ & $3(16)$ & $6(27)$ & $10(42)$ & $25(29)$ \\
\hline MNA, $\mathrm{n}(\%)^{2}$ & & & & & \\
\hline Well nourished ( $\geq 24$ points) & $8(38)$ & $5(26)$ & $11(52)$ & $10(42)$ & $34(40)$ \\
\hline Risk for UN (17-23.5 points) & $8(38)$ & $10(53)$ & $3(14)$ & $12(50)$ & $33(39)$ \\
\hline UN ( $\leq 17$ points $)$ & $5(24)$ & $4(21)$ & $7(33)$ & $2(8)$ & $18(21)$ \\
\hline
\end{tabular}

${ }^{1)}$ Internal attrition/drop-out $\mathrm{n}=1$ (orthopaedic ward), ${ }^{2)}$ Internal attrition/drop-out $\mathrm{n}=2$ (orthopaedic ward)

MEONF-II, Minimal Eating Observation and Nutrition Form - Version II; MNA, Mini Nutritional Assessment; NRS 2002, Nutritional Risk Screening 2002. 
Table 3 Diagnostic performance of the MEONF-II and NRS 2002 compared to the 18-item MNA $(n=85)$

\begin{tabular}{|c|c|c|c|c|c|c|c|c|c|}
\hline & \multicolumn{4}{|c|}{ Number of patients ${ }^{1}$} & \multirow[b]{2}{*}{$\begin{array}{l}\text { SENS }^{2} \\
(95 \% \mathrm{Cl})\end{array}$} & \multirow[b]{2}{*}{$\begin{array}{c}\text { SPEC }^{3} \\
(95 \% \mathrm{Cl})\end{array}$} & \multirow[b]{2}{*}{$\begin{array}{c}\text { PPV }^{4} \\
(95 \% \mathrm{Cl})\end{array}$} & \multirow[b]{2}{*}{$\begin{array}{c}\mathrm{NPV}^{5} \\
(95 \% \mathrm{Cl})\end{array}$} & \multirow[b]{2}{*}{ Accuracy ${ }^{6}$} \\
\hline & A & B & $\mathrm{C}$ & D & & & & & \\
\hline MEONF-II in relation to MNA & 31 & 7 & 20 & 27 & $\begin{array}{c}.61 \\
(.46-.74)\end{array}$ & $\begin{array}{c}.79 \\
(.62-.91)\end{array}$ & $\begin{array}{c}.82 \\
(.66-.92)\end{array}$ & $\begin{array}{c}.57 \\
(.42-.72)\end{array}$ & .68 \\
\hline \multirow[t]{2}{*}{ NRS 2002 in relation to MNA } & 19 & 6 & 32 & 28 & $\begin{array}{c}.37 \\
(.24-.52)\end{array}$ & $\begin{array}{c}.82 \\
(.65-.93)\end{array}$ & $\begin{array}{c}.76 \\
(.55-.91)\end{array}$ & $\begin{array}{c}.47 \\
(.34-.60)\end{array}$ & .55 \\
\hline & \multicolumn{4}{|c|}{ MNA } & & & & & \\
\hline Screening (MEONF-\|l or NRS 2002) & \multicolumn{2}{|c|}{ UN-risk/UN } & \multicolumn{2}{|c|}{ Not at risk } & & & & & \\
\hline UN-risk/UN & \multicolumn{2}{|c|}{ A } & \multicolumn{2}{|c|}{ B } & & & & & \\
\hline Not at risk & \multicolumn{2}{|c|}{ C } & \multicolumn{2}{|c|}{$\mathrm{D}$} & & & & & \\
\hline
\end{tabular}

The MNA has commonly been used as the comparator, or gold standard nutritional screening tool (e.g., $[7-9,15,20,21])$. MNA captures patients at risk also in an early stage so that preventive actions can be taken [12]. The NRS 2002 differs somewhat in focus in that its goal is to identify patients that are most likely to benefit from nutritional interventions $[4,15]$. It is therefore possible that the NRS 2002 is less suited for detecting patients in need for preventive actions than the MNA is. The intention of the MEONF-II, on the other hand is both to identify patients needing preventive nutritional interventions and those needing nutritional treatment.

Table 4 User-friendliness of the MNA, MEONF-II and NRS 2002, n = 87

\begin{tabular}{lcccc}
\hline & MNA & $\begin{array}{c}\text { NRS } \\
\mathbf{2 0 0 2}\end{array}$ & $\begin{array}{c}\text { MEONF- } \\
\text { II }\end{array}$ & $\begin{array}{c}\text { P-value } \\
\mathbf{1}\end{array}$ \\
\hline $\begin{array}{l}\text { Time to complete, minutes } \\
\text { median }\end{array}$ & 10 & 5 & 5 & $<\underset{2}{0.0005}$ \\
$\quad$ q1-q3 & $8-10$ & $2-10$ & $2-10$ & \\
$\quad$ min-max & $3-20$ & $1-20$ & $1-20$ & \\
$\begin{array}{l}\text { Instructions easy to understand, } \\
\text { \% }\end{array}$ & 93 & 93 & 99 & 0.165 \\
Items easy to understand, \% & 93 & 81 & 97 & $<\underset{3}{0.0005}$ \\
& & & & \\
Items easy to answer, \% & 85 & 75 & 96 & $<0.0005$ \\
& & & & 0.247
\end{tabular}

1) Friedman's two-way analysis of variance by ranks followed by post-hoc Wilcoxon signed ranks tests (time to complete), and Cochran's Q test followed by post-hoc McNemar tests (other data).

2) Significant difference between MNA and NRS 2002, MNA and MEONF-II (both comparisons $p=0.001 ; p=0.003$ following Bonferroni correction).

3) Significant difference between MNA and NRS 2002 ( $p=0.004 ; p=0.012$ following Bonferroni correction), and between NRS 2002 and MEONF-II ( $p=$ $0.001 ; p=0.003$ following Bonferroni correction).

4) Significant difference between NRS 2002 and MEONF-II ( $p=0.001 ; p=$ 0.003 following Bonferroni correction).

MNA, Mini Nutritional Assessment; MEONF-II, Minimal Eating Observation and Nutrition Form - Version II; NRS 2002, Nutrition Risk Screening 2002; q1-q3, inter-quartile range $\left(25^{\text {th }}-75^{\text {th }}\right.$ percentile).
Furthermore, the MNA was developed for people $\geq 65$ years [12,13], and the use of it as gold standard among younger patients can be questioned. However, we did not find any relevant differences between results from analyses of the full sample and when excluding the younger subsample. Thus, whether the MNA can be considered an appropriate gold standard or not depends on the intention with the comparator and possibly the age of the patients in the sample. In any case, people at risk for undernutrition need further assessments and no instrument can alone capture all aspects influencing the eating situation and the nutritional intake.

Cut-off scores used in the different instruments affect the results. The MNA cut-offs have been defined based on serum albumin values, a predictor of morbidity and mortality in elderly people $[13,14]$. This would suggest that any comparison with the MNA may only indicate whether low albumin levels can be detected. However, the MNA has also been validated against more extensive assessments of nutritional status (including, e.g., additional biomarkers and dietary parameters) [6]. The cutoff scores for MEONF-II have been defined based on clinical reasoning and confirmed by ROC analysis against the MNA classification [8,9], and the NRS 2002 cut-off was based on findings from randomized controlled trials regarding the effect of nutritional intervention [4]. However, the classification of patients in that study was done retrospectively and the authors were not blinded to outcome (usually artificial nutrition) when estimating the degree of undernutrition and severity of disease [4]. The different intentions of these instruments, the way they have been developed and compared with other measures affect the prevalence findings. For instance, in this study the NRS 2002 identified a significantly lower percentage (29\%) of patients as at risk than the MEONF-II (45\%) and MNA did (60\%). Similarly, in another study [15] the MNA identified 70\% of patients as at risk or malnourished while the NRS 2002 identified 
40\%. It therefore appears that the MEONF-II does not identify patients at risk as early as the MNA, and not as late as the NRS 2002. In clinical practice such differences will have consequences for preventive and treatment actions. Further on, a majority of those being undernourished according to MNA were correctly classified as at high risk by MEONF-II (13 out of 18 patients) or at risk by NRS 2002 (12 out of 18 patients). Anyhow, it should be remembered that the main purpose with screening is to identify people at risk and not to decide whether it is a low or high risk and that any case being at risk needs a more detailed assessment. In addition, efforts are needed to develop a clear vocabulary and uniform definitions of risk (low/high) and manifest undernutrition.

The MEONF-II showed a $68 \%$ concordance with the MNA, which is lower than that observed in a previous study (82\%) [8]. One explanation to the difference in accuracy could be that in the previous study [8], the assessment procedures were reviewed individually with the nurse assessors, whereas it was conducted as a group session in this study. However, the accuracy and sensitivity of the NRS 2002 found here (55\% and 37\%) are similar to those in previous studies of this instrument in relation to the MNA (52\% and 39\%) [15].

The MEONF-II is a screening tool designed to detect risk of undernutrition, not only those with manifest undernutrition. As such, it is reasonable for sensitivity to be given priority at the cost of specificity since overidentification is preferable to under-identification, given that positive screening results are followed by in-depth assessment [19,22]. In this respect the NRS 2002 appears less well suited, since its sensitivity was lower (37\%) compared to that of MEONF-II (61\%). However, as the associated 95\% CIs overlapped, additional studies in larger samples are needed before any firm conclusions can be drawn.

The MEONF-II demonstrated good user-friendliness in terms of time to complete, ease of understanding of items, as well as ease of completion. In these respects, our observations suggest that MEONF-II compares favourably to the NRS 2002. One reason for this may be that it helps nurses identifying problems and intervene directly, either themselves or by involving other professionals. It should be noticed that time consumption was low when using MEONF-II, despite the fact that this assessment was done before NRS 2002 and MNA. It could otherwise be expected that the time needed would be lower for tools used as second and third since several items are shared between the tools. One should, however, be careful in the interpretation of these findings since it was only four nurses that rated user-friendliness and there may be a learning curve for each of these nurses, affecting rating of user- friendliness and time needed for completing forms. Anyhow, user-friendliness is of fundamental importance for successful clinical implementation of nutritional screening tools. As most screenings are carried out by nurses, their perspective in this respect must be taken into account.

\section{Conclusion}

The MEONF-II is an easy to use, relatively quick and sensitive screening tool to assess risk of undernutrition among hospital inpatients. High sensitivity is of primary concern in nutritional screening. With respect to userfriendliness and sensitivity, the MEONF-II appears to perform well compared to the NRS 2002, although larger studies are needed for firm conclusions. The different scoring systems for undernutrition appear to identify overlapping but not identical patient groups. However, the appropriateness of using the MNA as gold standard among patients younger than 65 years can be questioned.

\section{Additional material}

Additional file 1: MEONF-II (Minimal Eating Observation and

Nutrition Form - Version II). The file contains the nutritional screening tool Minimal Eating Observation and Nutrition Form - Version II (MEONFII).

\section{Acknowledgements and Funding}

The authors wish to thank all participating patients and nurses for their cooperation. The study was supported by the Swedish Research Council and the Skåne County Council's Research and Development Foundation. The study was conducted in collaboration with the Patient Reported Outcomes Clinical Assessment Research and Education (PRO-CARE) group, Kristianstad University.

\section{Author details}

${ }^{1}$ The PRO-CARE group, School of Health and Society, Kristianstad University, Kristianstad, Sweden. ${ }^{2}$ Central Hospital, Kristianstad, Sweden.

\section{Authors' contributions}

All authors participated in the design of the study, read and approved the final manuscript. AW informed the data collectors, performed the statistical analysis, and drafted the manuscript. EN coordinated and supervised the data collectors. $\mathrm{PH}$ helped to draft the final manuscript.

\section{Competing interests}

The authors declare that they have no competing interests.

Received: 17 March 2011 Accepted: 20 December 2011 Published: 20 December 2011

\footnotetext{
References

1. Dey DK, Rothenberg E, Sundh V, Bosaeus I, Steen B: Body mass index, weight change and mortality in the elderly. A 15 y longitudinal population study of 70 y olds. Eur J Clin Nutr 2001, 55:482-492.

2. Locher JL, Roth DL, Ritchie CS, Cox K, Sawyer P, Bodner EV, Allman RM: Body mass index, weight loss, and mortality in community-dwelling older adults. J Gerontol A Biol Sci Med Sci 2007, 62:1389-1392.

3. Kondrup J, Allison SP, Elia M, Vellas B, Plauth M: ESPEN guidelines for nutrition screening 2002. Clin Nutr 2003, 22:415-421.
} 
4. Kondrup J, Rasmussen HH, Hamberg O, Stanga Z: Nutritional risk screening (NRS 2002): a new method based on an analysis of controlled clinical trials. Clin Nutr 2003, 22:321-336.

5. Guigoz Y, Vellas B, Garry PJ: Assessing the nutritional status of the elderly: The Mini Nutritional Assessment as part of the geriatric evaluation. Nutr Rev 1996, 54(1 Pt 2):S59-65

6. Vellas B, Guigoz Y, Garry PJ, Nourhashemi F, Bennahum D, Lauque S, Albarede JL: The Mini Nutritional Assessment (MNA) and its use in grading the nutritional state of elderly patients. Nutrition 1999, 15:116-122.

7. Stratton RJ, Hackston A, Longmore D, Dixon R, Price S, Stroud M, King C, Elia M: Malnutrition in hospital outpatients and inpatients: prevalence, concurrent validity and ease of use of the 'malnutrition universal screening tool' ('MUST') for adults. Br J Nutr 2004, 92:799-808.

8. Vallén $C$, Hagell $P$, Westergren A: Validity and user-friendliness of the The Minimal Eating Observation Form - Version II (MEONF-II) for undernutrition risk screening. Food Nutr Res 2011, 55:5801 [http://www. foodandnutritionresearch.net/index.php/fnr/article/view/5801]

9. Westergren A, Norberg E, Vallén C, Hagell P: Cut-off scores for the Minimal Eating Observation and Nutrition Form (MEONF-II) among hospital inpatients. Food Nutr Res 2011, 55:7289[http://www. foodandnutritionresearch.net/index.php/fnr/article/view/7289]

10. SWESPEN: Nutritionsbehandling i sjukvård och omsorg. Swedish Society for Clinical Nutrition and Metabolism. 2006.

11. Westergren A, Vallén C: Validity and reliability of the minimal eating observation and nutrition form (MEONF). Clinical Nutrition 2010, 5:61.

12. Guigoz $Y$, Lauque $S$, Vellas BJ: Identifying the elderly at risk for malnutrition. The Mini Nutritional Assessment. Clin Geriatr Med 2002, 18:737-757.

13. Guigoz Y, Vellas B, Garry PJ: Mini Nutritional Assessment: a practical assessment tool for grading the nutritional state of elderly patients. Facts Res Gerontol 1994, 4(Suppl 2):15-59.

14. Bauer JM, Kaiser MJ, Anthony P, Guigoz Y, Sieber CC: The Mini Nutritional Assessment-its history, today's practice, and future perspectives. Nutr Clin Pract 2008, 23:388-396

15. Bauer JM, Vogl T, Wicklein S, Trogner J, Muhlberg W, Sieber CC Comparison of the Mini Nutritional Assessment, Subjective Global Assessment, and Nutritional Risk Screening (NRS 2002) for nutritional screening and assessment in geriatric hospital patients. Z Gerontol Geriatr 2005, 38:322-327.

16. Westergren A, Lindholm C, Mattsson A, Ulander K: Minimal eating observation form: reliability and validity. J Nutr Health Aging 2009 13:6-12.

17. Westergren A, Unosson M, Ohlsson O, Lorefalt B, Hallberg IR: Eating difficulties, assisted eating and nutritional status in elderly ( $>$ or $=65$ years) patients in hospital rehabilitation. Int J Nurs Stud 2002, 39:341-351.

18. Altman D: Practical statistics for medical research. London: Chapman \& Hall; 1990.

19. Loong TW: Understanding sensitivity and specificity with the right side of the brain. BMJ 2003, 327:716-719.

20. Charlton KE, Kolbe-Alexander TL, Nel JH: Development of a novel nutrition screening tool for use in elderly South Africans. Public Health Nutr 2005, 8:468-479

21. Soderhamn U, Flateland S, Jessen L, Soderhamn O: Norwegian version of the Nutritional Form for the Elderly: sufficient psychometric properties for performing institutional screening of elderly patients. Nutr Res 2009, 29:761-767.

22. Kaiser MJ, Bauer JM, Ramsch C, Uter W, Guigoz Y, Cederholm T, Thomas DR Anthony P, Charlton KE, Maggio M, Tsai AC, Grathwohl D, Vellas B, Sieber CC, MNA-International Group: Validation of the Mini Nutritional Assessment short-form (MNA-SF): a practical tool for identification of nutritional status. J Nutr Health Aging 2009, 13:782-788.

\section{Pre-publication history}

The pre-publication history for this paper can be accessed here: http://www.biomedcentral.com/1472-6955/10/24/prepub

\section{doi:10.1186/1472-6955-10-24}

Cite this article as: Westergren et al:: Diagnostic performance of the Minimal Eating Observation and Nutrition Form - Version II (MEONF-II) and Nutritional Risk Screening 2002 (NRS 2002) among hospital inpatients - a cross-sectional study. BMC Nursing 2011 10:24.

\section{Submit your next manuscript to BioMed Central and take full advantage of:}

- Convenient online submission

- Thorough peer review

- No space constraints or color figure charges

- Immediate publication on acceptance

- Inclusion in PubMed, CAS, Scopus and Google Scholar

- Research which is freely available for redistribution

Submit your manuscript at www.biomedcentral.com/submit 